\title{
The science of anthropogenic climate change: what every doctor should know
}

In this Analysis article (BMJ 2014;349:g5178, doi:10.1136/bmj. g5178), we wrongly spelt out an acronym for climate change scenarios. RCPs should have been defined as representative (not "relative") concentration pathways. In addition, figure 7 shows the geographical pattern of warming in the latter part of the 21st century, not the 20th century, as is stated in the fifth paragraph of the section headed "What can we say about future climate change." The print journal version of the article has been corrected.

Cite this as: BMJ 2014;349:96005

๑ BMJ Publishing Group Ltd 2014 